\title{
A mechanistic role for the chromatin modulator, NAP1L1, in pancreatic neuroendocrine neoplasm proliferation and metastases
}

\author{
Simon Schimmack ${ }^{1,2}$, Andrew Taylor ${ }^{1}$, Ben Lawrence ${ }^{1}$, Daniele Alaimo ${ }^{1}$, Hubertus Schmitz-Winnenthal ${ }^{2}$, \\ Markus W Büchler ${ }^{2}$, Irvin M Modlin ${ }^{1}$ and Mark Kidd ${ }^{1 *}$
}

\begin{abstract}
Background: The chromatin remodeler NAP1L1, which is upregulated in small intestinal neuroendocrine neoplasms (NENs), has been implicated in cell cycle progression. As p57 $7^{\mathrm{Kip2}}$ (CDKN1C), a negative regulator of proliferation and a tumor suppressor, is controlled by members of the NAP1 family, we tested the hypothesis that NAP1L1 may have a mechanistic role in regulating pancreatic NEN proliferation through regulation of p57 $7^{\text {Kip2 }}$.

Results: NAP1L1 silencing (siRNA and shRNA/lipofectamine approach) decreased proliferation through inhibition of mechanistic (mammalian) target of rapamycin pathway proteins and their phosphorylation $(p<0.05)$ in the pancreatic neuroendocrine neoplasm cell line BON in vitro $(p<0.0001)$ and resulted in significantly smaller $(p<0.05)$ and lighter $(p<0.05)$ tumors in the orthotopic pancreatic NEN mouse model. Methylation of the $p 57^{\text {Kip2 }}$ promoter was decreased by NAP1L1 silencing $(p<0.05)$, and expression of $\mathrm{p} 57^{\mathrm{Kip} 2}$ (transcript and protein) was upregulated. For methylation of the $p 57^{\text {Kip } 2}$ promoter, NAP1L1 bound directly to the promoter (-164 to +21, chromatin immunoprecipitation). In 43 pancreatic NEN samples (38 primaries and 5 metastasis), NAP1L1 was over-expressed in metastasis $(p<0.001)$, expression which was inversely correlated with $p 57^{\text {Kip2 }}(p<0.01)$ on mRNA and protein levels. Menin was not differentially expressed.
\end{abstract}

Conclusion: NAP1L1 is over-expressed in pancreatic neuroendocrine neoplasm metastases and epigenetically promotes cell proliferation through regulation of $p 57^{\text {Kip2 }}$ promoter methylation.

Keywords: NAP1L1, Pancreatic neuroendocrine neoplasms, pNETs, Promoter methylation, p57, Proliferation

\section{Background}

Pancreatic neuroendocrine neoplasms (pNENs) are an aggressive form of cancer that are derived from a heterogeneous population of endocrine cells [1]. While approximately $5 \%$ of tumors exhibit germ-line mutations in MEN-1, VHL, NF-1, or TSC [2], the pathogenesis of the majority of lesions remains ill-understood [3]. Recently, sequencing of sporadic pNENs identified mutations in chromatin remodeling genes including menin (in 44\% of the cases) and DAXX/ATRX (43\%) [4]. The epigenome therefore is a potential target in the etiopathology of pNENs.

\footnotetext{
* Correspondence: mark.kidd@yale.edu

${ }^{1}$ Gastrointestinal Pathobiology Research Group, Yale University School of Medicine, PO Box 208602, New Haven, CT, 06510, USA

Full list of author information is available at the end of the article
}

One gene that was not mutated was nucleosome assembly protein 1-like 1 (NAP1L1). NAP1L1 belongs to a family which is thought to be involved in nucleosome assembly and exchange of histone H2A-H2B dimmers [5-7], as well as transcriptional regulation and cell cycle progression [8]. Inactivation of NAP1 significantly alters gene expression profiles [9], while deletion of NAP1L2 results in embryonic lethality [10]. NAP1L2, NAP1L3, and NAP1L5 [11-14] are neuron-specific and play a role in neuronal differentiation, proliferation, and apoptosis [15]. NAP1-like proteins have similar activities regarding nucleosome assembling; NAP1L1, however, displays the highest disassembly activity [16]. Increased expression of NAP1L1 may be related to cell growth, as levels of both NAP1L1 mRNA and protein increase rapidly in conjunction with cell proliferation in a T-lymphoid cell model 
[17]. NAP1L1 is also over-expressed in fetal liver compared with adult liver [18], in hepatoblastoma compared to healthy adult liver [19], and in $50 \%$ of colon cancer [20]. In addition, NAP1L1 is elevated in malignant adenocarcinoids compared to normal mucosa [21] and has been reported to be over-expressed in small intestinal NENs [22]. Little, however, is known regarding its expression and potential role in the pathogenesis of pNENs.

The regulation of cell cycle inhibitors such as the CDK inhibitor $\mathrm{p} 57^{\mathrm{Kip} 2}$ (CDKN1C) is controlled by members of the NAP1 family [15], suggesting one mechanism by which NAP1L1 could regulate proliferation. P57 ${ }^{\mathrm{Kip} 2}$ is highly expressed in $G_{0} / G_{1}$ and decreases during progression through $G_{1}-S$ simultaneously with the activation of cyclin-CDK complexes [23,24]. Accordingly, over-expression of $\mathrm{p} 57^{\mathrm{Kip} 2}$ induces $\mathrm{G}_{1}$ arrest in cultured cells [25]. In pancreatic adenocarcinomas, p57 ${ }^{\mathrm{Kip} 2}$ protein is decreased in $>50 \%$ of lesions which correlates with more aggressive forms [26,27]. In endocrine neoplasms, p57 ${ }^{\text {Kip2 }}$ expression was absent in $75 \%$ of malignant adrenocortical tumors [28], and in a second study in 47 adrenal tissues, no $\mathrm{p} 57^{\mathrm{Kip} 2}$ mutations were evident but a decreased expression was detected in malignant tumors [29].

We hypothesized that NAP1L1 played a role in regulating cell entry into the S-phase through transcriptional regulation of factors that controlled neuroendocrine cell growth and proliferation. We considered that $\mathrm{p} 57^{\mathrm{Kip} 2}$, as a tumor suppressor, would be silenced in proliferating/ neoplastic neuroendocrine cells as a consequence of NAP1L1 activity. Since one of the major inherited genes involved in pancreatic NENs is menin, a known growth inhibitor and chromatin remodeler [30,31], we also examined its expression to assess whether it was associated with NAP1L1 and $\mathrm{p} 57^{\mathrm{Kip} 2}$. We used a dataset of well-characterized pancreatic NENs (Heidelberg, Yale collections [32]) as well as the BON cell line [32,33] as a model to examine the function of NAP1L1.

\section{Results}

\section{NAP1L1 knockdown and tumor cell signaling in vitro} Initially, we examined the effect of NAP1L1 silencing in the BON cell line. NAP1L1 was silenced 3-fold $(p<0.001)$ as demonstrated at both protein (Figure 1A) and mRNA (Figure 1B) levels. This was associated with an increase in p57 ${ }^{\text {Kip2 }}$ mRNA $(p<0.01)$ and protein. While menin mRNA did not change, protein increased in NAP1L1-silenced cells. Growth signaling pathways were also altered by NAP1L1 silencing. Specifically, mechanistic (mammalian) target of rapamycin (mTOR) and phosphorylated mTOR was reduced in NAP1L1-silenced down cells (Figure 1C). Consequently, downstream effectors such as eukaryotic initiation factor 4E-binding protein (4E-BP1) as well as S6 kinase (S6K1), which mTOR regulates through phosphorylation [34], were reduced (Figure 1D,E, $p<0.05$ ).
Additionally, mRNA expression of ribosomal proteins including S24 (RPS24) and ribosomal protein L28 (RPL28) were also decreased as expected [35] when NAP1L1 was silenced (Figure 1F, $p<0.05$ ). The ERK pathway was unaffected (Figure 1B). This suggests that NAP1L1 may promote proliferation via mTOR signaling.

\section{NAP1L1 and tumor cell proliferation in vitro}

To evaluate the expression of NAP1L1, p57 $7^{\mathrm{Kip} 2}$, and menin during cell proliferation, we first examined protein expression during the different phases of the cell cycle (Figure 2A). In proliferating BON cells (2 days of growth in normal media), quiescent $\left(G_{0} / G_{1}\right)$ and cycling ( $S$ and $\left.\mathrm{G}_{2} / \mathrm{M}\right)$ cell populations were evenly divided. The shift to quiescence by 2 days of serum deprivation ( $80 \%$ of the cells were in $G_{0} / G_{1}$ phase, Figure $2 A$ ) was associated with decreased NAP1L1 $(p<0.05)$ and increased P57 ${ }^{\mathrm{Kip} 2}$ protein expression $(p<0.05)$ (Figure $2 \mathrm{~B}$ ); menin was not increased (Figure 2B). Pharmaceutical inhibition of growth factor signaling pathways with either BEZ235 (targeting mTOR) or GSK1120212 (targeting ERK) generated similar alterations. Inhibition of these growth factor signaling pathways tended to decreased NAP1L1 $(p=0.06)$ and concomitantly increased $p 57^{\text {Kip } 2}$ mRNA expression $(p<0.05)$, while menin did not alter (Figure $2 \mathrm{C}$ ).

To investigate a role for NAP1L1 in tumor proliferation, the effect of NAP1L1 knockdown in BON cells was evaluated in BrdU incorporation assays. Cells were studied over a 4-day period. By $48 \mathrm{~h}$, there was a significant elevation in BrdU uptake in non-silenced/normal BON cells compared to NAP1L1-silenced BON cells (Figure 2D, $p<0.0001$, approximately 40 -fold) as well as a marked decrease in the number of cells in these experiments (Figure 2D).

\section{NAP1L1 and tumor cell proliferation in vivo}

We next examined whether NAP1L1-silencing reduced tumor formation in an orthotopic pNEN mouse model. Transfection with shRNA was associated with a $70 \%$ internalization of the plasmid by fluorescence microscopy (Figure 3A). Three weeks after BON cell implantation $\left(1.5 \times 10^{6}\right.$ cells, viability approximately $\left.90 \%\right)$ into the pancreas tail at laparotomy, all mice in the control group $(n=4)$ had developed palpable tumors on the left upper side of the stomach. In contrast, only two of the five mice, injected with NAP1L1 knockdown cells, had tumors at 4 weeks. Both were small tactile tumors. After 6 weeks, we euthanized all nine mice (four with injection of control BON cells and five with injection of NAP1L1 knockdown BON cells) and found liver metastases in two of the four mice in the control group; all four mice had additional peritoneal metastases. None of the knockdown group exhibited any macroscopic evidence of metastases (Figure 3B). Pancreatic tumors in the control group were 


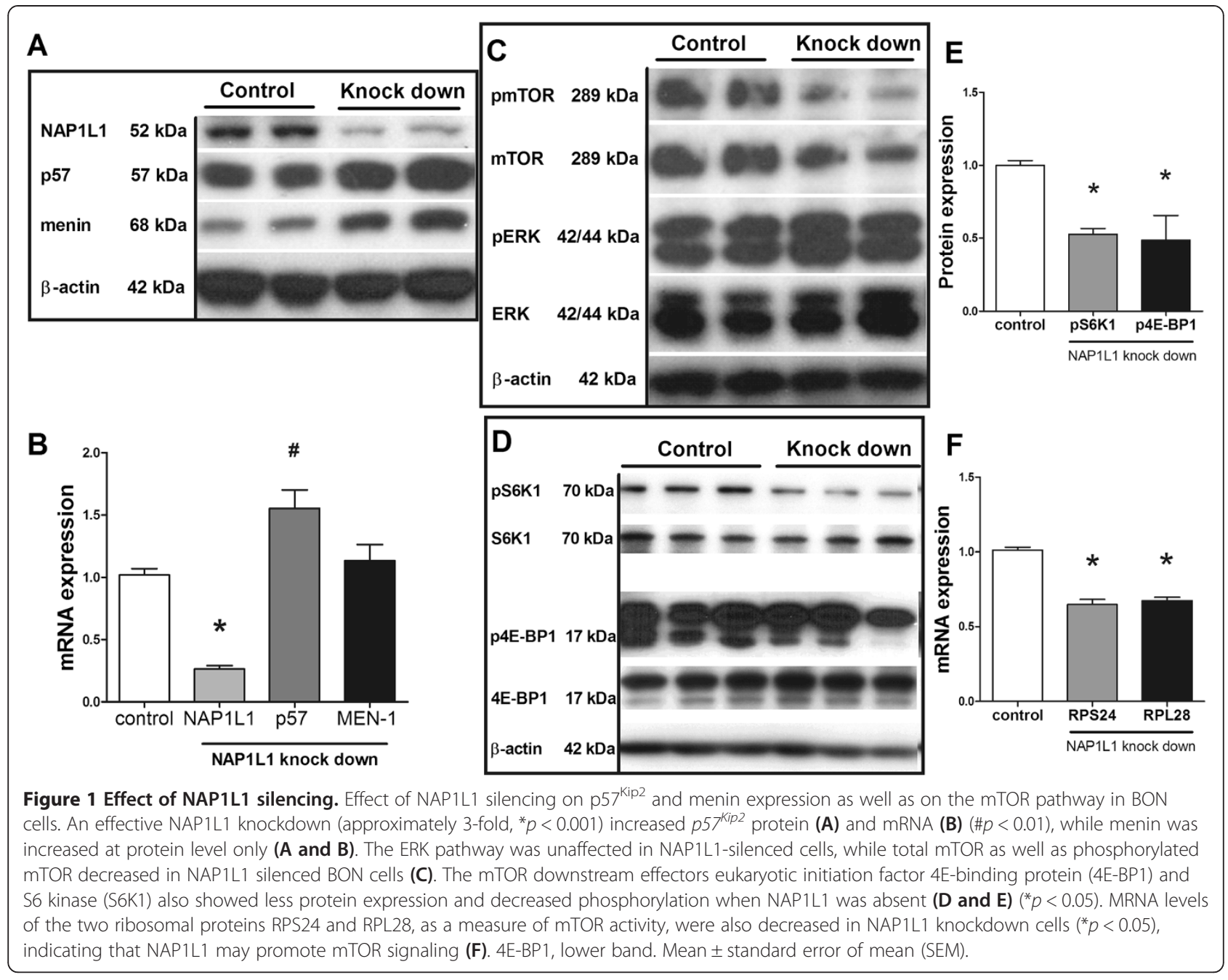

larger $\left(51.75 \pm 19.23 \mathrm{~mm}^{3}\right)$ and heavier (wet weight, $3.14 \pm$ $0.95 \mathrm{~g}$ ) in comparison to the NAP1L1 knockdown group $\left(17.48 \pm 4.12 \mathrm{~mm}^{3}\right.$ and $\left.1.57 \pm 0.29 \mathrm{~g}, p<0.05\right)$ (Figure $3 \mathrm{C}$, D). At an mRNA level, a decreased NAP1L1 expression in knockdown tumors $(p<0.05)$ was confirmed (Figure 3E). Blood samples demonstrated a lower chromogranin A (CgA) serum expression in mice which had been injected with NAP1L1-knockdown cells (Figure 3F, $p<0.05$ ) suggesting that CgA may, as in humans [36], be a marker of tumor burden. Its expression also correlated with tumor size $(r=0.88, p<0.01)$ and weight $(r=0.9, p<0.01)$ (data not shown). Histopathologically, a decrease in NAP1L1 expression was noted in knockdown tumors while the protein was highly expressed in liver metastases (Figure 3G). Expression of CgA was similar in normal and NAP1L1 knockdown tumors; metastases expressed less CgA (Figure 3G).

\section{NAP1L1 controls $p 57^{\text {Kip2 }}$ expression by direct binding to its promoter}

To investigate mechanisms by which NAP1L1 regulated proliferation, we examined the methylation status of the $p 57^{\text {Kip } 2}$ promoter region in normal and NAP1L1silenced BON cells. As demonstrated (Figure 4A), a highly methylated (=silenced $p 57^{\text {Kip } 2}$ ) promoter was detected in untreated BON cells. In contrast, the promoter was significantly less methylated $(p<0.05)$ in NAP1L1silenced cells which suggested that NAP1L1 may be necessary for the maintenance of $p 57^{\text {Kip2 }}$ promoter methylation and therefore inhibition of $p 57^{K i p 2}$ transcription. We used ChIP analysis to examine whether NAP1L1 directly interacted with the $p 57^{\text {Kip } 2}$ promoter. In normal growing BON cells, NAP1L1-bound DNA fragments contained the $p 57^{K i p 2}$ promoter region $(-164$ to +21 ) (Figure $4 \mathrm{~B})$. In low-proliferating BON cells (2-day serum deprivation), no binding of NAP1L1 to the $p 57^{\text {Kip } 2}$ promoter was detected. We interpret these results to provide an explanation for the increased $\mathrm{p} 57^{\mathrm{Kip} 2}$ protein expression (no NAP1L1 binding and therefore inhibition, coupled to activation through known $p 57^{K i p 2}$ transcriptional regulators, e.g., HDACI/II) [37] in serum-deprived BON cells (Figure 2B). 

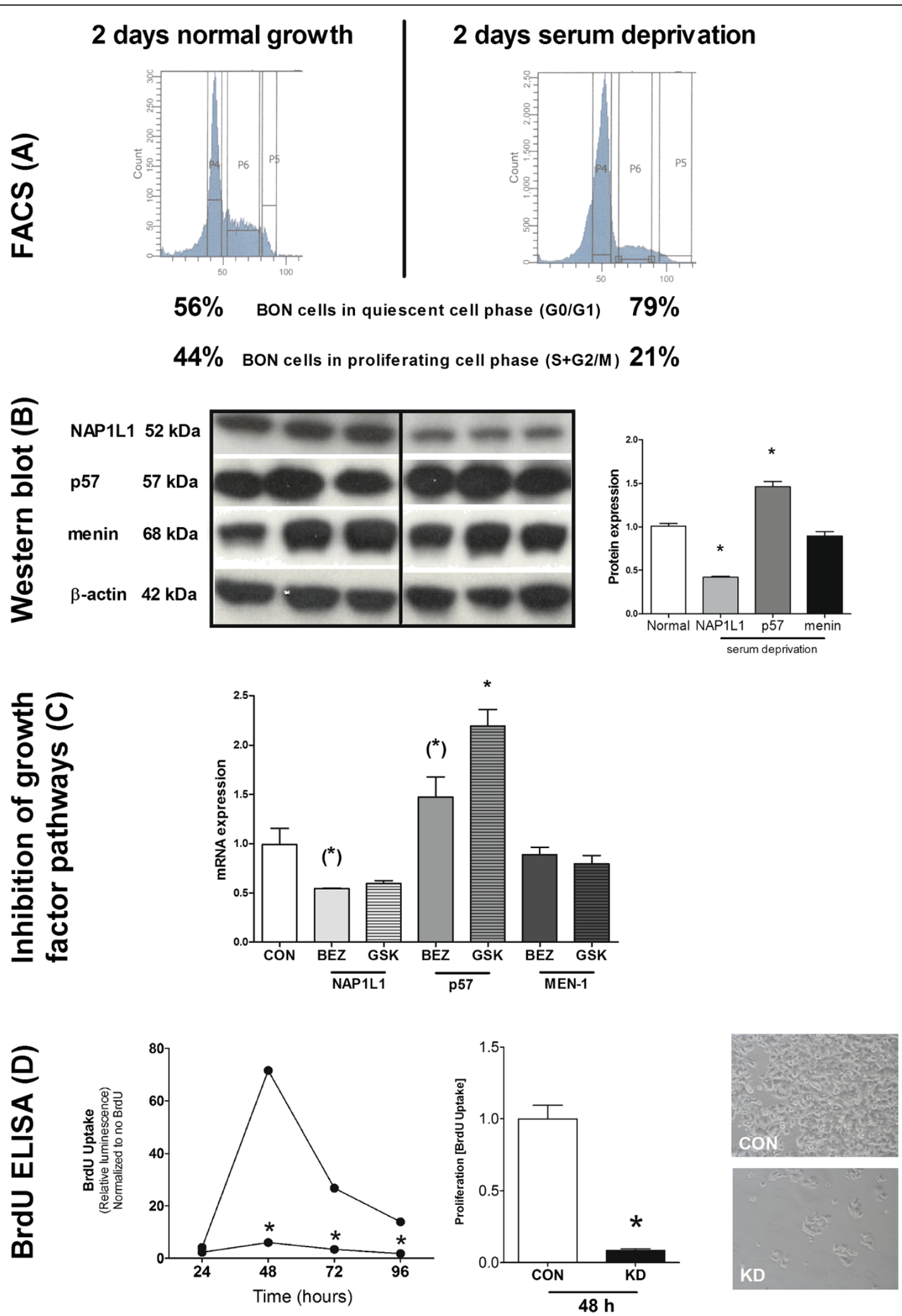

Figure 2 (See legend on next page.) 
(See figure on previous page.)

Figure 2 The effect of NAP1L1 on tumor cell proliferation in vitro. In proliferating BON cells, 56\% were in the quiescent cell phase $\left(\mathrm{G}_{0} / \mathrm{G}_{1}\right)$ and $44 \%$ in the proliferating cell phase $\left(S\right.$ and $\left.G_{2} / M\right)$. After two days of serum deprivation, $80 \%$ of the cells were quiescent (A). A decrease of NAP1L1 ( $\left.{ }^{*} p<0.05\right)$ and an increase of $p 57^{\mathrm{Kip} 2}\left({ }^{*} p<0.05\right)$ protein expression were evident (B). Inhibiting proliferation by targeting the mTOR pathway (BEZ235) and ERK pathway (GSK1120212) resulted in a similar pattern of expression: NAP1L1 tended to be decreased ((*) $p=0.06)$ and p57 $7^{\text {Kip2 }}$ was increased $\left({ }^{*} p<0.05\right)$ while menin did not alter $(\mathbf{C})$. BON cells without NAP1L1 did not grow $\left({ }^{*} p<0.0001\right)$ and exhibited decreased cell numbers (D). Mean \pm SEM.

\section{Screening of NAP1L1, p57 ${ }^{\mathrm{Kip} 2}$, and menin expression in normal and neoplastic pancreas}

To evaluate whether the in vitro and in vivo mechanistic observations were clinically relevant, we screened NAP1L1, p57 ${ }^{\text {Kip2 }}$, and menin in ten normal pancreas and 43 pNEN samples. NAP1L1 mRNA was overexpressed in pNEN primaries $(p<0.01)$ and pNEN metastasis $(p<0.01)$ compared to normal pancreas (Figure $5 \mathrm{~A}$, Kruskal-Wallis $p<0.001)$. In contrast to these findings, $p 57^{\text {Kip } 2}$ mRNA was almost completely downregulated in metastases versus normal pancreas (Figure 5B, $p<0.01$ ). Menin mRNA expression was not different in this pNEN sample set compared to normal tissue (Figure 5C). In addition, we identified a positive correlation between NAP1L1 mRNA levels and Ki67 $(r=0.64, p<0.0001), C g A$ $(r=0.42, p<0.001)$, Chromogranin $B(r=0.61, p<0.0001)$, and the pNEN biomarker, INA [32] $(r=0.64, p<0.0001)$ (data not shown). NAP1L1 expression was also positively correlated with tumor size (Figure 5D, Spearman's $r=0.4$, $p<0.05)$. The mRNA results were confirmed on protein level (Figure 5E): NAP1L1 was over-expressed in pNEN primaries $(p<0.05)$ and pNEN metastasis $(p<0.05)$ compared to normal pancreas (Figure $5 F, D)$, while $\mathrm{p} 57^{\text {Kip } 2}$ protein levels were higher in normal pancreas than in pNENs $(p<0.05$, Figure 5G,D). Menin protein expression was also not different in this pNEN sample set compared to normal pancreatic tissue (Figure 5H,D).

\section{Discussion}

The etiology and tumorigenesis of pancreatic NENs, which are the most aggressive form of gastroenteropancreatic NENs [38], remain poorly understood. Epigenetic modifications are unarguably one of the major mechanisms for pNEN pathogenesis [4]. In the present study, we examined the expression and function of chromatin modulator NAP1L1 in pancreatic NENs. While other NAP1 family members, e.g., NAP1L2, NAP1L3, and NAP1L5 [11-14] are well known to be neuron-specific and play a role in proliferation [15] and the NAP1 family is associated with transcriptional regulation [8], our current results define a role for NAP1L1 in the transcriptional regulation of pancreatic neuroendocrine neoplasm cell cycle progression. Specifically, our results highlight a role for this family member as an inhibitor of p $57^{\text {Kip2 }}$.

The current studies demonstrate (1) that NAP1L1 was over-expressed, while $\mathrm{p} 57^{\mathrm{Kip} 2}$ was downregulated in
pNENs, (2) that NAP1L1 is involved in the mTOR pathway signaling, (3) that NAP1L1 was essential for proliferation in vitro and in an orthotopic pNEN mouse model, and (4) that one mechanism of NAP1L1-mediated cell proliferation control may occur through inhibition of p5 $7^{\text {Kip2 }}$ transcription.

$\mathrm{P} 57^{\mathrm{Kip} 2}$ has many functions; as it can arrest the cell cycle, promote apoptosis, and inhibit angiogenesis as well as its downregulation in many cancers [39], it qualifies as a tumor suppressor. It is also important in embryogenesis; $p 57^{K i p 2}$-null mice exhibit high neonatal mortality with severe developmental defects [40]. In neoplasia, downregulation of $\mathrm{p} 57^{\mathrm{Kip} 2}$ promotes cell migration, and invasion in human nasopharyngeal carcinoma cells [41] and decreased expression were associated with poor postsurgical survival time and lymphatic metastasis in lung cancer [42] as well as in other cancer types [25,39], e.g., in hepatocellular [43] or pancreatic [27] carcinoma. Our studies confirmed downregulation of $\mathrm{p} 57^{\mathrm{Kip} 2}$ in pNENs and suggest one mechanism for this phenomenon. The promoter region of the $p 57^{\text {Kip } 2}$ gene is rich in CpG islands and promoter methylation is a well-described mechanism to explain attenuated expression in cancers [39]. In a panel of tumor cell lines and primary cancer cells, dense $p 57^{\text {Kip } 2}$ promoter CpG methylation was identified at the transcription start site [44]. We determined a role for NAP1L1 in the regulation of $p 57^{\text {Kip } 2}$ promoter methylation in $\mathrm{BON}$ cells by direct promoter binding of NAP1L1. NAP1-like proteins have previously been reported to control gene expression through histone H3 acetylation [15]. Methylation, through a NAP1L1complex, is therefore a novel mechanism for $p 57^{\text {Kip2 }}$ transcriptional control that may be applicable to other neoplasia. This is supported by studies with demethylating agents (5-azacytidine or 5-aza-2' -deoxycytidine) which results in $p 57^{\text {Kip } 2}$ re-expression or over-expression in several experimental cancer models $[45,46]$. Our observations suggest a direct link between NAP1L1 and p57 $7^{\mathrm{Kip} 2}$. Targeting NAP1L1 (through silencing) increased the expression of $\mathrm{p} 57^{\mathrm{Kip} 2}$ and resulted in significant decreases in both DNA synthesis as well as metastasis in vivo. Mechanistically, NAP1L1 bound to SP1/CTIP2 sites that are involved in HDAC-mediated transcriptional regulation of $p 57^{K i p 2}$ [37]. These sites are dissimilar to those identified for NAP1L2 binding in the promoter region in ES-derived differentiated neurons [15]. As 


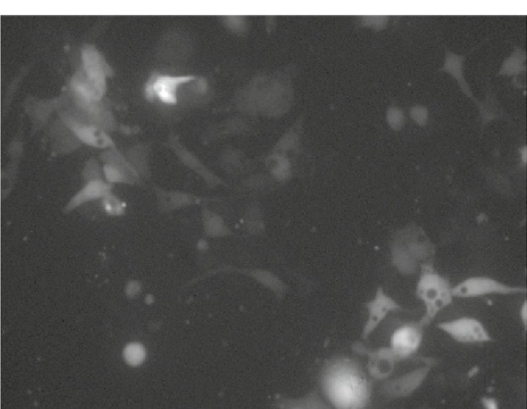

A
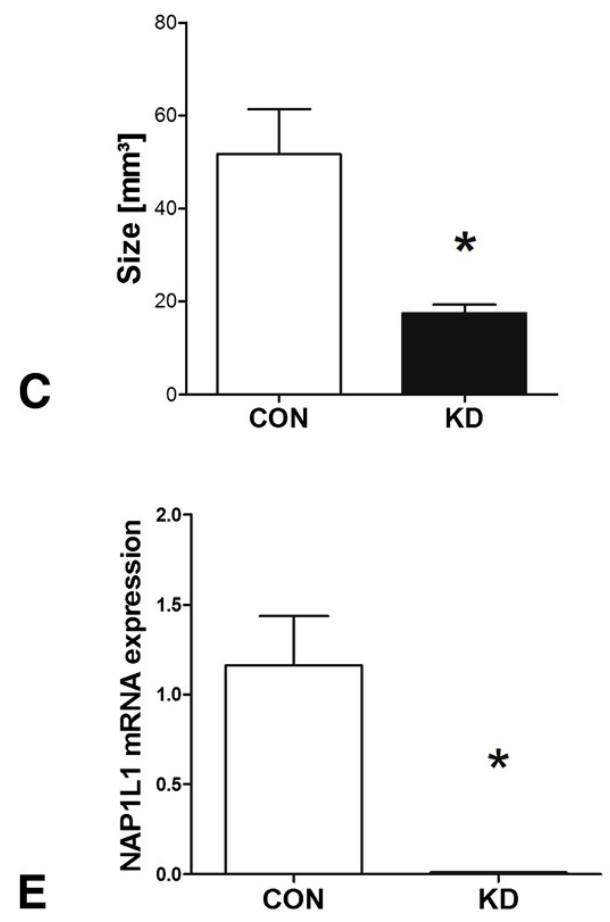

B CON KD

D
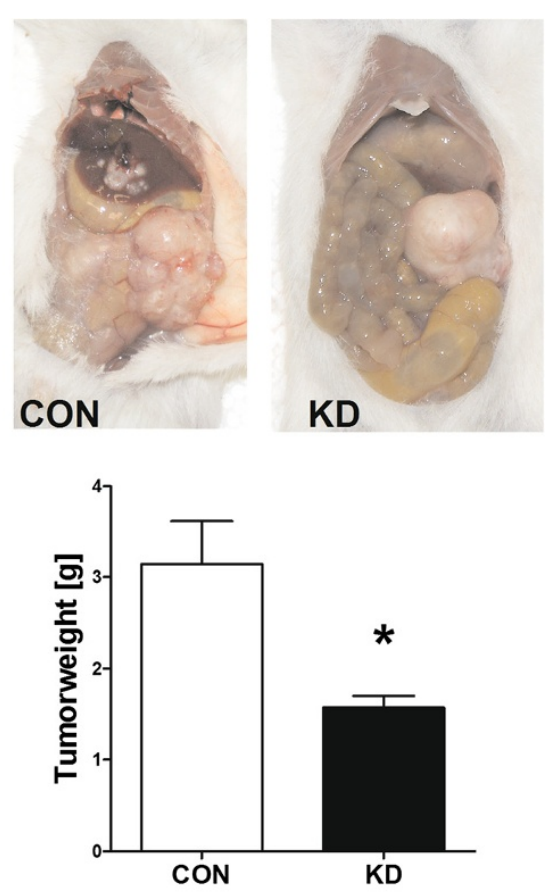

$\mathbf{F}$

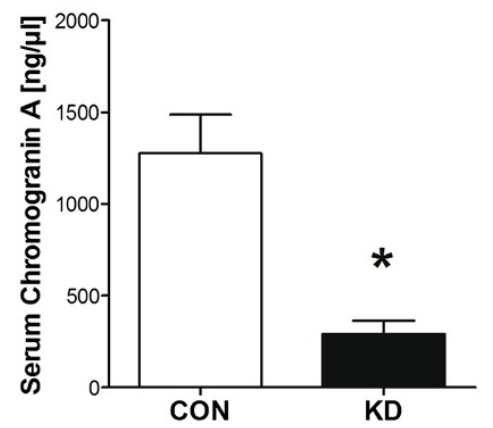

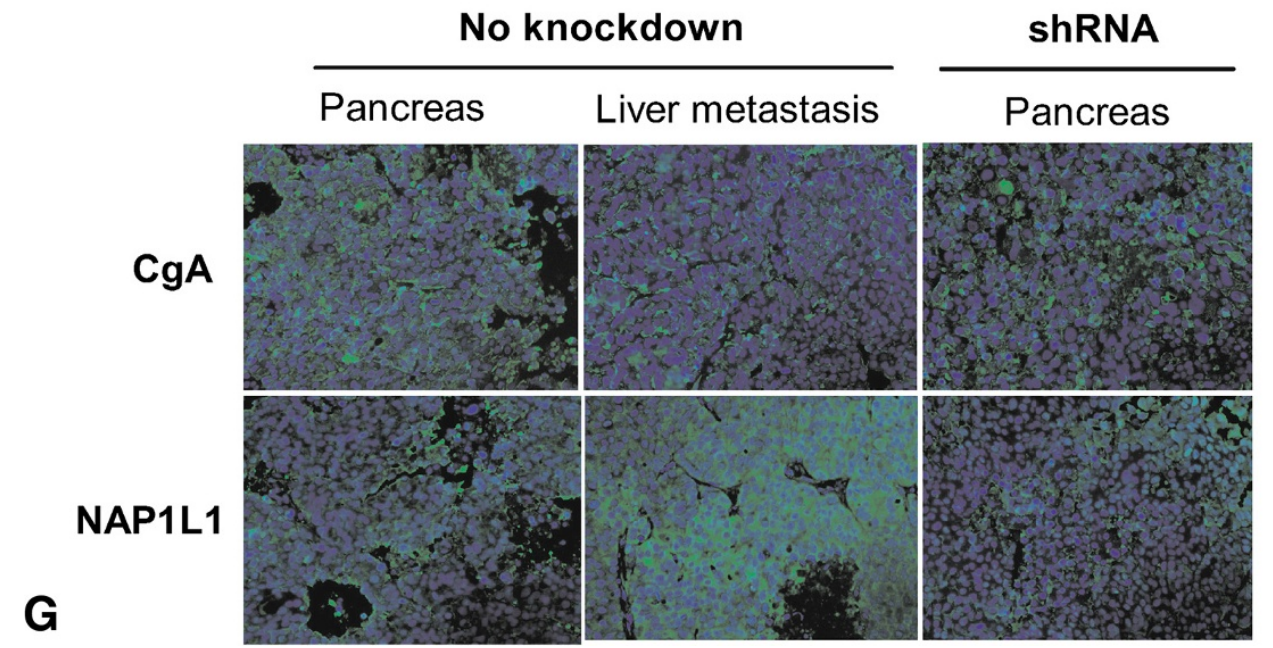

Figure 3 (See legend on next page.) 
(See figure on previous page.)

Figure 3 Impact of NAP1L1 silencing of tumor growth in an orthotopic pNEN mouse model. After having established stable NAP1L1 knockdown BON cells (confirmation of shRNA internalization by fluorescence microscopy (A) and thereafter puromycin-selection), we injected $1.5 \times 10^{6}$ transfected cells in $100 \mu \mathrm{lPBS}$ into the pancreas tail of nine Ns/J-mice by flank-laparotomy (CON $=4$ mice, $\left.\mathrm{KD}=5 \mathrm{mice}\right)$. Six weeks after pancreas injection, necroscopy identify large tumors with metastases in control injected mice (B), while KD-injected mice had smaller (C) $\left(^{*} p<0.05\right)$ and lighter (D) $\left(^{*} p<0.05\right)$ tumors that were all localized. KD tumors expressed less NAP1L1 than controls (E and G). Circulating chromogranin A (CgA) levels were also decreased in serum of KD mice (F) $\left.{ }^{*} p<0.05\right)$, and expression of this marker was lower in the liver metastases $(\mathbf{G})$. Mean \pm SEM.

NAP1L2 is associated with transcriptional repression through increased levels of acetylated histone H3K9/14, we conclude that NAP1L1 may inhibit transcription either by a similar mechanism or through inhibition of SP1mediated activity [47].

The principal growth factor signaling pathway also affected by NAP1L1-silencing was the mTOR pathway. We identified that NAP1L1 knockdown both reduced phosphorylation of downstream mTOR effectors including 4E-BP1 as well as S6K1 and was associated with a decreased ribosomal RNA expression, all markers consistent with mTOR inhibition [35]. The ERK pathway, in contrast, was unaffected (Figure 1B). This suggests that NAP1L1 may promote proliferation via mTOR signaling. Since mutations of this pathway have been reported in $15 \%$ of pNENs [4], a role for NAP1L1 in this pathway may be of clinical relevance.

Menin, also a tumor suppressor, is one of the gene products predominantly mutated in pNENs $[4,30]$. The mechanism(s) of menin-driven tumor pathogenesis, however, remain unclear $[2,48]$. Menin can function as a histone-methyltransferase and is reported to have an anti-proliferative regulatory effect in pancreatic islet cells through histone H3K4 methylation and regulation of cell cycle inhibitors [49]. We anticipated that menin expression would be decreased in BON cells and clinical samples. We could not identify an altered expression in clinical samples or in the cell line (consistent with previous reports [50,51]). One reason may be the absence of MEN1 mutations in our sample set. A second reason might be that despite a mutation of one menin allele, menin mRNA is detectable by PCR while the meninantibody used (Cell Signaling Technology) recognizes all three isoforms of menin. This suggests that menin expression is not linked to NAP1L1-mediated effects. However, we did identify that menin protein expression was increased in NAP1L1 silenced cells which suggests that NAP1L1 may function to negatively regulate menin expression. This potentially identifies an additional role for NAP1L1 in pNEN pathogenesis.

\section{Conclusions}

Our data identifies that NAP1L1 epigenetically promotes tumor cell proliferation in pancreatic neuroendocrine

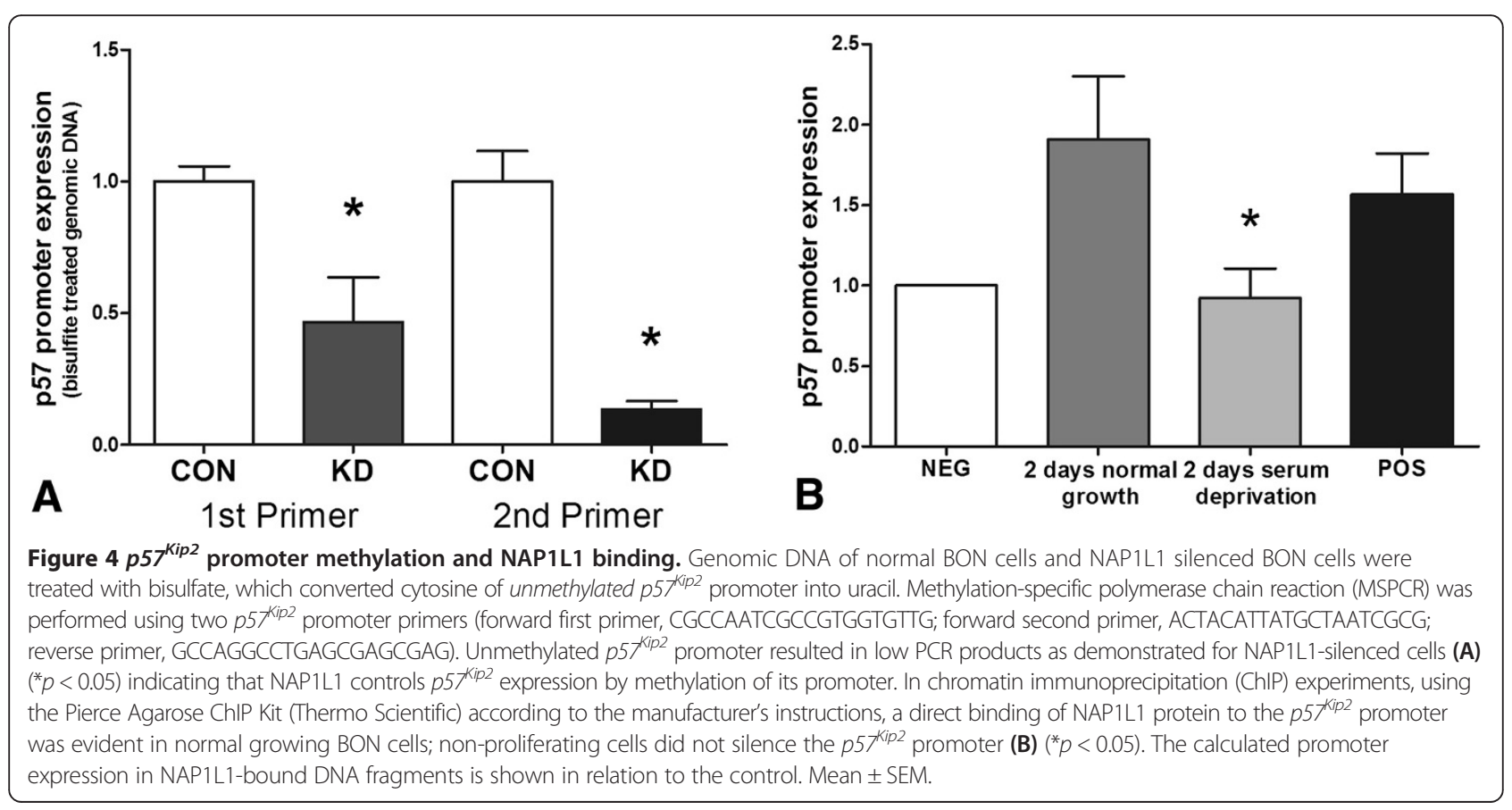




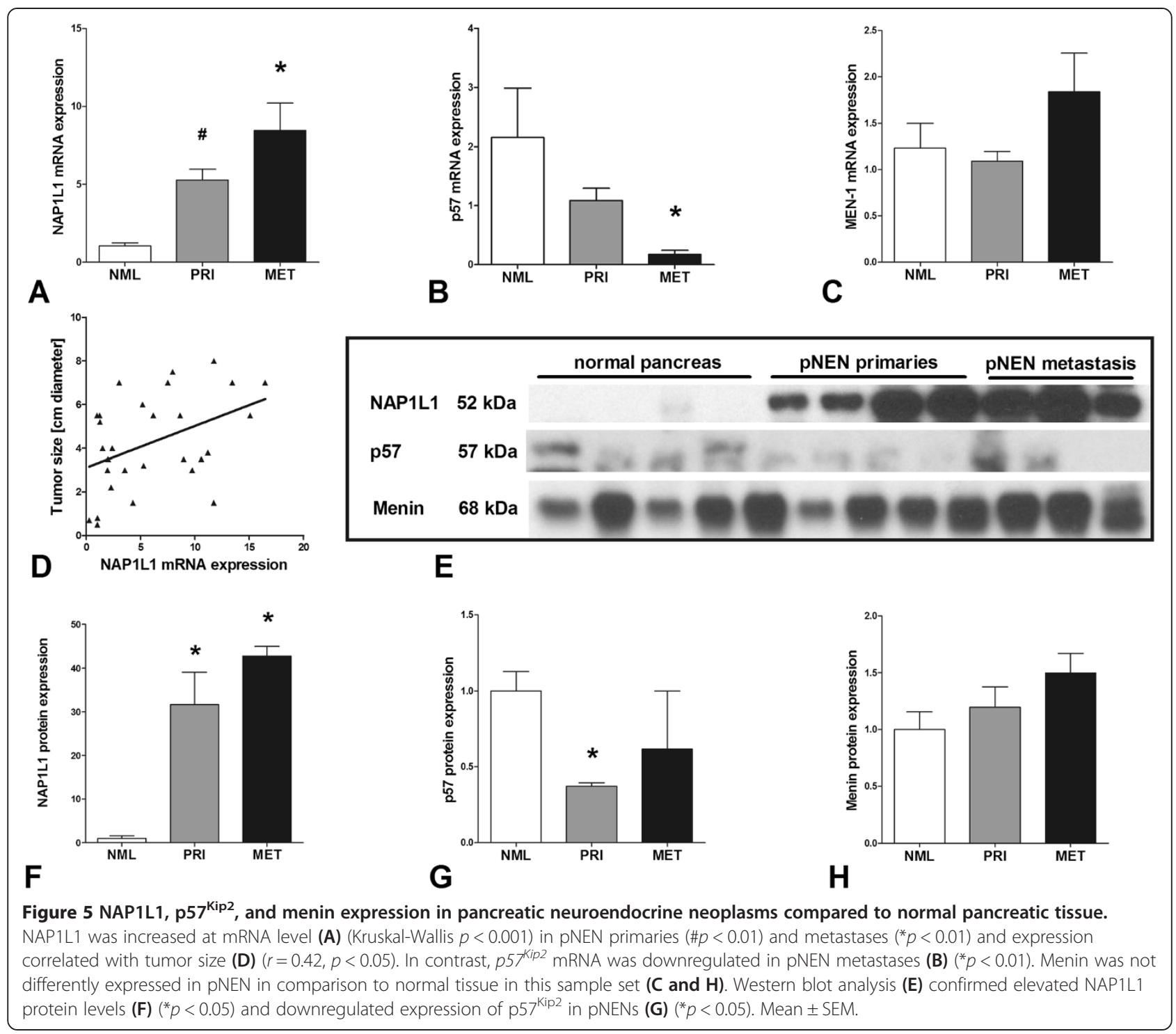

neoplasms through inhibition of the mTOR pathway and the tumor suppressor $\mathrm{p} 57^{\mathrm{Kip} 2}$; the principal mechanism is via $\mathrm{p} 57^{\mathrm{Kip} 2}$ promoter methylation. This turns NAP1L1 into a promising target for anti-cancer therapy.

\section{Methods}

\section{Cell lines}

To investigate mechanistic roles and the importance of NAP1L1 in proliferation, we used the adherent human metastasized pancreatic neuroendocrine neoplasm (NEN) cell line, BON [33], authenticated by STR (Genetica DNA Laboratories, Cincinnati, OH, USA). The cells were cultivated in medium containing RPMI 1640, Hams' F12 (Gibco, Grand Island, NY, USA; 1:1 ratio), 10\% FBS and penicillin/streptomycin $(100 \mathrm{IU} / \mathrm{ml})$ in $75 \mathrm{~cm}^{2}$ flasks (Sarstedt, Newton, NC, USA) as described [32].

\section{NAP1L1 knockdown}

To assess the role of NAP1L1 in cell proliferation, we seeded $1.6 \times 10^{5}$ BON cells/well in 6-well plates (Falcon, BD, Franklin Lakes, NJ, USA) and silenced NAP1L1 using reverse transfection with siRNA (sequence GGUAGAA ACACCAACAGGAUACAUU, $140 \mathrm{pmol} /$ well) and Lipofectamine RNAiMAX (Invitrogen, Carlsbad, CA, USA). We confirmed the knockdown using PCR and Western blot after 24-96 h. Control cells were treated with Lipofectamine and scrambled siRNA.

\section{Proliferation assay}

To investigate the role of NAP1L1, $557^{\mathrm{Kip} 2}$, and menin in cell proliferation, we first cultured BON cells $\left(2.5 \times 10^{5}\right.$ / well) in 6-well plates (Falcon, BD, Franklin Lakes, NJ, USA) under normal conditions with (normal/logarithmic 
growth) and without serum (starvation/quiescent) and harvested them after 2 days for FACS (to determine the cell cycle kinetics of those BON cells, see FAC-sorting section) and protein isolation. In a second set of experiments, we used a BrdU (bromodeoxyuridine) chemiluminescence ELISA (Roche Diagnostics, Indianapolis, IN, USA) to investigate the proliferation of normal and NAP1L1silenced BON cells according to the manufacturers' instructions. Briefly, NAP1L1-silenced BON cells were labeled in 12-well plates (Falcon) with BrdU solution and incubated for $3 \mathrm{~h}$. After fixation and DNA denaturation, BrdU incorporation, as a measurement of cell division, was quantitated using a chemiluminescence assay (GLOMAX Luminometer, Promega, Madison, WI, USA).

\section{Inhibition of the PI3K/mTOR and MAP-kinase pathway}

We evaluated growth signaling and expression of NAP1L1, $p 57^{\text {Kip } 2}$, and menin using selective pharmaceutical compounds that specifically inhibited growth-signaling-pathway kinases. We seeded BON cells $\left(3 \times 10^{5}\right.$ cells/well $)$ in 6-well plates (Falcon) for $24 \mathrm{~h}$ and treated these cells with GSK1120212 [MAPK pathway inhibitor (target MEK1/2) $-10^{-7} \mathrm{M}$ ) and BEZ235 [mTOR pathway inhibitor (target $\left.\mathrm{PI}_{3} \mathrm{~K} / \mathrm{PKB}\right)-10^{-8} \mathrm{M}$ ) for $24 \mathrm{~h}$ prior to mRNA collection. Cells were harvested by adding TRIZOL $^{\oplus}$ (Invitrogen, Carlsbad, CA, USA) (see Isolation of RNA and genomic DNA, reverse transcription, and quantitative PCR section).

\section{FAC-sorting}

To quantify the cell cycle phases of BON cell after serum deprivation versus logarithmic growth (see Proliferation assay section), we harvested those BON cells and after $15 \mathrm{~min}$ incubation with propidium iodide/PBS (1:50, Roche, Indianapolis, IN, USA) conducted flow cytometry (BD FACS Aria Cell Sorter, BD Biosciences, Bedford, MA, USA). Cell cycle alterations were analyzed using FloJo Software 31 (TreeStar, Mountain View, CA, USA) [52].

\section{Orthotopic murine xenograft model}

To assess the role of NAP1L1 in tumor cell proliferation in vivo, we attempted to establish a permanent NAP1L1 knockdown BON cell line by transfection of a NAP1L1shRNA plasmid containing puromycin resistance gene and GFR luminescence (GeneCopoeia, Rockville, MD, USA) via Lipofectamine RNAiMAX (Invitrogen). Because proliferation of those cells was decreased so significantly following transfection (see Figure 2D), we could not culture the necessary number of cells for in vivo experiments. As an alternative, we grew BON cells in $75 \mathrm{~cm}^{2}$ flasks (Sarstedt) and transfected them in these flasks overnight in antibiotic-free medium. After confirming the internalization of the plasmid through fluorescence microscopy
(488 nm), stable shRNA clones were selected via growth media containing $3 \mu \mathrm{g} / \mathrm{ml}$ puromycin (Invitrogen) and cells were harvested after $48 \mathrm{~h}$ (viability $77 \%-90 \%$ ). We injected $1.5 \times 10^{6}$ of the transfected cells or control BON cells (Lipofectamine treatment, viability $>90 \%$ ) in $100 \mu \mathrm{l}$ PBS into the pancreas tail of nine Ns/J-mice (Jackson Laboratory, Bar Harbor, ME, USA) by flank-laparotomy under anesthesia [53]. All mice were euthanized 6 weeks after BON cell implantation, and circulating blood and tumor tissue were collected. All animals were treated according to IRB standards of the Yale University.

\section{Human sample collection}

The collection of pancreatic tissue from patients with pNENs $(n=43)$ and normal pancreas $(n=10)$ was obtained according to the Ethics Committee requirements for the University of Heidelberg, Germany and an IRB protocol at Yale University [32]. Quality control was assured by a pathologist experienced with NEN histopathology. Only samples in which histology demonstrated more than $70 \%$ tumor were included. As only five patients had died, survival analysis was not undertaken.

\section{Protein extraction and western blot analysis}

Tissue $(1 \times 2 \mathrm{~mm})$ or cell line lysates were manually homogenized (PYREX homogenizer; VWR, Radnor, PA, USA) and prepared as previously described [32]. Supernatant protein was quantified (Pierce BCA protein assay kit; Thermo Scientific, Rockford, IL, USA), total protein lysates $(15 \mu \mathrm{g})$ were denaturated in SDS sample buffer, separated on an SDS-PAGE gel [10\% or $4 \%-20 \%$ (mTOR and 4E-BP1)], and transferred to a PVDF membrane (Bio-Rad, Hercules, CA, USA; pore size $0.45 \mathrm{~mm}$ ). Primary antibodies included anti-NAP1L1 (Abcam, Cambridge, MA, USA), anti-p57 ${ }^{\text {Kip2 }}$, anti-menin-1, anti-phosphoERK, anti-ERK, anti-phospho-mTOR, anti-mTOR, antiphospho-S6K1, anti-S6K1, anti-phospho-4E-BP1, and anti-4E-BP1 (all from Cell Signaling Technology, Beverly, MA, USA). Immunodetection was performed using Western Lightning $^{\mathrm{Tm}}$ Plus-ECL (PerkinElmer, Waltham, MA, USA). Protein levels were confirmed with $\beta$-actin (Sigma-Aldrich, St. Louis, MO, USA). The optical density of the appropriately sized bands was measured using ImageJ software (NIH, Bethesda, MD, USA). The ratio between target protein expression and control protein was calculated.

Isolation of RNA and genomic DNA, reverse transcription, and quantitative PCR

Messenger RNA was extracted from each tissue samples (or cell lines) using TRIZOL $^{\oplus}$ (Invitrogen, Carlsbad, CA, USA) and cleaned (RNeasy kit, Qiagen, Valencia, CA, USA). After conversion to cDNA (high-capacity cDNA Archive Kit, Applied Biosystems, Carlsbad, CA, USA), 
quantitative PCR (qPCR) analyses were performed using Assays-on Demand ${ }^{\mathrm{Tm}}$ and the ABI 7900 Sequence Detection System. Primer sets were all obtained from Applied Biosystems. PCR data was normalized using the $\Delta \Delta C_{\mathrm{T}}$ method; ALG9 was used as a housekeeping gene [54].

The extraction of genomic DNA was performed using the MasterPure Complete DNA and RNA Purification Kit (EPICENTRE, Madison, WI, USA) according to the manufacturers' instructions and quantified by Nanodrop (Thermo Scientific).

\section{$p 57^{\text {Kip2 }}$ promoter methylation}

To investigate the status of $p 57^{\text {Kip } 2}$ promoter methylation, we treated genomic DNA of normal BON cells and NAP1L1-silenced BON cells with bisulfate, which caused conversion of unmethylated cytosines into uracil. This was undertaken using the Methyl Code Bisulfite Conversion Kit (Invitrogen) according to the manufacturers' instructions. MSPCR was performed using two primers which bound to the $p 57^{\text {Kip } 2}$ promoter region (NCBI reference sequence NG_008022.1) (first forward primer, CGCCAATCGCC GTGGTGTTG [-164 to -141$]$; second forward primer, ACTACATTATGCTAATCGCG [-126 to -107$]$; reverse primer, GCCAGGCCTGAGCGAGCGAG) $[+2$ to +21$]$ ). The forward primers encompass SP1 and CTIP2 binding sites involved in HDAC-mediated transcriptional regulation [37]. Unmethylated promoter resulted in low PCR products in this assay.

\section{Chromatin immunoprecipitation}

To examine whether NAP1L1 directly bound to the $p 57^{\text {Kip } 2}$ promoter, we performed ChIP using the Pierce Agarose ChIP Kit (Thermo Scientific). Briefly, we fixed the crosslinks between DNA and protein by formaldehyde, lysed the cells, and digested chromatin using micrococcal nuclease. Of these DNA fragments, $10 \%$ was used as input control. After immunoprecipitation with a ChIP-gradeNAP1L1-antibody (Santa Cruz Biotechnology, Santa Cruz, CA, USA), DNA fragments were purified and qPCR performed using primers for detecting the $p 57^{K i p 2}$ promoter (see above). We used normal rabbit IgG as negative and anti-RNA polymerase II antibody and GAPDH promoter primers as positive controls. The $p 57^{\text {Kip } 2}$ promoter expression in NAP1L1-bound DNA fragments was calculated relative to the control.

\section{Statistical evaluation}

All statistical analyses were performed using Microsoft Excel and Prism 5 (GraphPad Software, San Diego, CA, USA). Comparisons between more than two groups were performed using the Kruskal-Wallis test, followed by the Dunn's post hoc test where appropriate. Binary comparisons were made using a 2-tailed Mann-Whitney $U$ test. Correlations were undertaken using Spearman's correlation. A $p$ value of $<0.05$ was designated as significant. Statistical significance is indicated by an asterisk and described in the figure legends. Bars without an asterisk did not reach significance.

\section{Abbreviations}

BrdU: bromdesoxyuridin; CgA: chromogranin A; ChIP: chromatin immunoprecipitation; HDAC: histone deacetylase; INA: internexin alpha; MEN-1: multiple endocrine neoplasia 1; mTOR: mechanistic (mammalian) target of rapamycin; NAP1L1: nucleosome assembly protein 1-like 1; NF-1: neurofibromatosis 1; pNENs: pancreatic neuroendocrine neoplasms; RPL28: ribosomal protein L28; RPS24: ribosomal protein S24; S6K1: S6 kinase 1; TSC: tuberous sclerosis complex; VHL: Von Hippel-Lindau disease; 4E-BP1: eukaryotic initiation factor 4E-binding protein.

\section{Competing interests}

The authors declare that they have no competing interests.

\section{Authors' contributions}

MK, IM, and SS generated the main idea of the work and developed the study design, both conceptually and methodologically. AT and DA carried out methylation studies, isolation of mRNA and protein as well as Western blot and PCR. BL, MK, and SS contributed to analysis and interpretation of the data. HSW and MB contributed materials. SS and MK wrote the manuscript. BL, HSW, MB, and IM were involved in interpretation of data and critical revision for important intellectual content. All authors read and approved the final manuscript.

\section{Acknowledgements}

We thank Michael Stankewich, PhD, Department of Pathology, for the experienced and kind assistance in fluorescence imaging. SS was supported by the German Research Association SCHI 1177/1-1.

\section{Author details}

'Gastrointestinal Pathobiology Research Group, Yale University School of Medicine, PO Box 208602, New Haven, CT, 06510, USA. ²Department of General, Visceral and Transplantation Surgery, University Hospital Heidelberg, Im Neuenheimer Feld 110, Heidelberg 69120, Germany.

Received: 24 December 2013 Accepted: 8 July 2014

Published: 21 July 2014

\section{References}

1. Schimmack S, Svejda B, Lawrence B, Kidd M, Modlin IM: The diversity and commonalities of gastroenteropancreatic neuroendocrine tumors. Langenbecks Arch Surg 2011, 396:273-298.

2. Calender A: Molecular genetics of neuroendocrine tumors. Digestion 2000, 62(Suppl 1):3-18.

3. Modlin IM, Oberg $K$, Chung DC, Jensen RT, de Herder WW, Thakker RV, Caplin M, Delle Fave G, Kaltsas GA, Krenning EP, Moss SF, Nilsson O, Rindi G, Salazar R, Ruszniewski P, Sundin A: Gastroenteropancreatic neuroendocrine tumours. Lancet Oncol 2008, 9:61-72.

4. Jiao Y, Shi C, Edil BH, de Wilde RF, Klimstra DS, Maitra A, Schulick RD, Tang LH, Wolfgang CL, Choti MA, Velculescu VE, Diaz LA, Vogelstein B, Kinzler KW, Hruban HW: Papadopoulos N: DAXX/ATRX, MEN1, and mTOR pathway genes are frequently altered in pancreatic neuroendocrine tumors. Science 2011, 331:1199-1203.

5. Kimura H, Takizawa N, Allemand E, Hori T, Iborra FJ, Nozaki N, Muraki M, Hagiwara M, Krainer AR, Fukagawa T, Okawa K: A novel histone exchange factor, protein phosphatase $2 \mathrm{Cgamma}$, mediates the exchange and dephosphorylation of H2A-H2B. J Cell Biol 2006, 175:389-400.

6. Okuwaki M, Kato K, Shimahara H, Tate S, Nagata K: Assembly and disassembly of nucleosome core particles containing histone variants by human nucleosome assembly protein I. Mol Cell Biol 2005, 25:10639-10651

7. Park YJ, Chodaparambil JV, Bao Y, McBryant SJ, Luger K: Nucleosome assembly protein 1 exchanges histone $\mathrm{H} 2 \mathrm{~A}-\mathrm{H} 2 \mathrm{~B}$ dimers and assists nucleosome sliding. J Biol Chem 2005, 280:1817-1825.

8. Zlatanova J, Seebart C, Tomschik M: Nap1: taking a closer look at a juggler protein of extraordinary skills. FASEB J 2007, 21:1294-1310. 
9. Ohkuni K, Shirahige K, Kikuchi A: Genome-wide expression analysis of NAP1 in Saccharomyces cerevisiae. Biochem Biophys Res Commun 2003, 306:5-9.

10. Rogner UC, Spyropoulos DD, Le Novere N, Changeux JP, Avner P: Control of neurulation by the nucleosome assembly protein-1-like 2. Nat Genet 2000, 25:431-435.

11. Rougeulle C, Avner P: Cloning and characterization of a murine brain specific gene Bpx and its human homologue lying within the Xic candidate region. Hum Mol Genet 1996, 5:41-49.

12. Shen $\mathrm{HH}$, Huang AM, Hoheisel J, Tsai SF: Identification and characterization of a SET/NAP protein encoded by a brain-specific gene, MB20. Genomics 2001, 71:21-33.

13. Smith RJ, Dean W, Konfortova G, Kelsey G: Identification of novel imprinted genes in a genome-wide screen for maternal methylation. Genome Res 2003, 13:558-569.

14. Watanabe TK, Fujiwara T, Nakamura Y, Hirai Y, Maekawa H, Takahashi E: Cloning, expression pattern and mapping to Xq of NAP1L3, a gene encoding a peptide homologous to human and yeast nucleosome assembly proteins. Cytogenet Cell Genet 1996, 74:281-285.

15. Attia M, Rachez C, De Pauw A, Avner P, Rogner UC: Nap1/2 promotes histone acetylation activity during neuronal differentiation. Mol Cell Biol 2007, 27:6093-6102.

16. Okuwaki M, Kato K, Nagata K: Functional characterization of human nucleosome assembly protein 1-like proteins as histone chaperones. Genes Cells 2010, 15:13-27.

17. Simon HU, Mills GB, Kozlowski M, Hogg D, Branch D, Ishimi Y, Siminovitch KA: Molecular characterization of hNRP, a cDNA encoding a human nucleosome-assembly-protein-I-related gene product involved in the induction of cell proliferation. Biochem J 1994, 297(Pt 2):389-397.

18. Nagata T, Takahashi $Y$, Ishii $Y$, Asai S, Sugahara M, Nishida Y, Murata A, Chin M, Schichino H, Koshinaga T, Fukuzawa M, Mugishima H: Profiling of genes differentially expressed between fetal liver and postnatal liver using high-density oligonucleotide DNA array. Int J Mol Med 2003, 11:713-721.

19. Nagata T, Takahashi $Y$, Ishii $Y$, Asai $S$, Nishida $Y$, Murata A, Koshinaga T, Fukuzawa M, Hamazaki M, Asami K, Ito E, Ikeda H, Takamatsu H, Koike K, Kikuta A, Kuroiwa M, Watanabe A, Kosaka Y, Fujita H, Miyake M, Mugishima H: Transcriptional profiling in hepatoblastomas using high-density oligonucleotide DNA array. Cancer Genet Cytogenet 2003, 145:152-160.

20. Line A, Slucka Z, Stengrevics A, Silina K, Li G, Rees RC: Characterisation of tumour-associated antigens in colon cancer. Cancer Immunol Immunother 2002, 51:574-582.

21. Modlin IM, Kidd M, Latich I, Zikusoka MN, Eick GN, Mane SM, Camp RL: Genetic differentiation of appendiceal tumor malignancy: a guide for the perplexed. Ann Surg 2006, 244:52-60.

22. Kidd M, Modlin IM, Mane SM, Camp RL, Eick G, Latich I: The role of genetic markers-NAP1L1, MAGE-D2, and MTA1-in defining small-intestinal carcinoid neoplasia. Ann Surg Oncol 2006, 13:253-262.

23. Polyak K, Kato JY, Solomon MJ, Sherr CJ, Massague J, Roberts JM, Koff A: p27Kip1, a cyclin-Cdk inhibitor, links transforming growth factor-beta and contact inhibition to cell cycle arrest. Genes Dev 1994, 8:9-22.

24. Toyoshima H, Hunter T: p27, a novel inhibitor of G1 cyclin-Cdk protein kinase activity, is related to p21. Cell 1994, 78:67-74.

25. Borriello A, Caldarelli I, Bencivenga D, Criscuolo M, Cucciolla V, Tramontano A, Oliva A, Perrotta S, Della Ragione F: p57(Kip2) and cancer: time for a critical appraisal. Mol Cancer Res 2011, 9:1269-1284.

26. Ito Y, Takeda T, Wakasa K, Tsujimoto M, Matsuura N: Expression of p57/Kip2 protein in pancreatic adenocarcinoma. Pancreas 2001, 23:246-250.

27. Sato N, Matsubayashi H, Abe T, Fukushima N, Goggins M: Epigenetic down-regulation of CDKN1C/p57KIP2 in pancreatic ductal neoplasms identified by gene expression profiling. Clin Cancer Res 2005, 11:4681-4688.

28. Bourcigaux N, Gaston V, Logie A, Bertagna X, Le Bouc Y, Gicquel C: High expression of cyclin E and G1 CDK and loss of function of p57KIP2 are involved in proliferation of malignant sporadic adrenocortical tumors. J Clin Endocrinol Metab 2000, 85:322-330.

29. Barzon L, Chilosi M, Fallo F, Martignoni G, Montagna L, Palu G, Boscaro M: Molecular analysis of CDKN1C and TP53 in sporadic adrenal tumors. Eur $J$ Endocrinol 2001, 145:207-212.

30. Wu X, Hua X: Menin, histone h3 methyltransferases, and regulation of cell proliferation: current knowledge and perspective. Curr Mol Med 2008, 8:805-815.
31. Yang YJ, Song TY, Park J, Lee J, Lim J, Jang H, Kim YN, Yang JH, Song Y, Choi A, Lee HY, Jo CH, Han JW, Kim ST, Youn HD, Cho EJ: Menin mediates epigenetic regulation via histone $\mathrm{H} 3$ lysine 9 methylation. Cell Death Dis 2013, 4:e583.

32. Schimmack S, Lawrence B, Svejda B, Alaimo D, Schmitz-Winnenthal $H$, Fischer L, Buchler MW, Kidd M, Modlin I: The clinical implications and biologic relevance of neurofilament expression in gastroenteropancreatic neuroendocrine neoplasms. Cancer 2012, 118:2763-2775

33. Evers BM, Townsend CM Jr, Upp JR, Allen E, Hurlbut SC, Kim SW, Rajaraman S, Singh P, Reubi JC, Thompson JC: Establishment and characterization of a human carcinoid in nude mice and effect of various agents on tumor growth. Gastroenterology 1991, 101:303-311.

34. Hay N, Sonenberg N: Upstream and downstream of mTOR. Genes Dev 2004, 18:1926-1945.

35. Kazi AA, Hong-Brown L, Lang SM, Lang CH: Deptor knockdown enhances mTOR activity and protein synthesis in myocytes and ameliorates disuse muscle atrophy. Mol Med 2011, 17:925-936. doi: 910.2119/molmed.2011.00070. Epub 02011 May 00019.

36. Modlin IM, Gustafsson BI, Moss SF, Pavel M, Tsolakis AV, Kidd M: Chromogranin A-biological function and clinical utility in neuro endocrine tumor disease. Ann Surg Oncol 2010, 17:2427-2443.

37. Cucciolla V, Borriello A, Criscuolo M, Sinisi AA, Bencivenga D, Tramontano A, Scudieri AC, Oliva A, Zappia V, Della Ragione F: Histone deacetylase inhibitors upregulate p57Kip2 level by enhancing its expression through Sp1 transcription factor. Carcinogenesis 2008, 29:560-567. doi: 510.1093/ carcin/bgn1010. Epub 2008 Jan 1019.

38. Lawrence B, Gustafsson BI, Chan A, Svejda B, Kidd M, Modlin IM: The epidemiology of gastroenteropancreatic neuroendocrine tumors. Endocrinol Metab Clin North Am 2011, 40:1-18. vii.

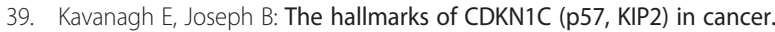
Biochim Biophys Acta 2011, 1816:50-56.

40. Yan Y, Frisen J, Lee MH, Massague J, Barbacid M: Ablation of the CDK inhibitor p57Kip2 results in increased apoptosis and delayed differentiation during mouse development. Genes Dev 1997, 11:973-983.

41. Chow SE, Wang JS, Lin MR, Lee CL: Downregulation of p57kip(2) promotes cell invasion via LIMK/cofilin pathway in human nasopharyngeal carcinoma cells. J Cell Biochem 2011, 112:3459-3468.

42. Biaoxue R, Xiguang C, Hua L, Hui M, Shuanying Y, Wei Z, Wenli S, Jie D: Decreased expression of decorin and p57(KIP2) correlates with poor survival and lymphatic metastasis in lung cancer patients. Int J Biol Markers 2011, 26:9-21.

43. Schwienbacher C, Gramantieri L, Scelfo R, Veronese A, Calin GA, Bolondi L, Croce CM, Barbanti-Brodano G, Negrini M: Gain of imprinting at chromosome 11p15: a pathogenetic mechanism identified in human hepatocarcinomas. Proc Natl Acad Sci U S A 2000, 97:5445-5449.

44. Kikuchi T, Toyota M, Itoh F, Suzuki H, Obata T, Yamamoto H, Kakiuchi H, Kusano M, Issa JP, Tokino T, Imai K: Inactivation of p57KIP2 by regional promoter hypermethylation and histone deacetylation in human tumors. Oncogene 2002, 21:2741-2749.

45. Garcia-Manero G, Kantarjian HM, Sanchez-Gonzalez B, Yang H, Rosner G, Verstovsek S, Rytting M, Wierda WG, Ravandi F, Koller C, Xiao L, Faderl S, Estrov Z, Cortes J, O'brien S, Estey E, Bueso-Ramos C, Fiorentino J,

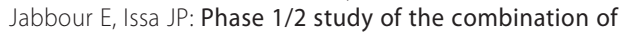
5-aza-2'-deoxycytidine with valproic acid in patients with leukemia. Blood 2006, 108:3271-3279.

46. Qiu X, Hother C, Ralfkiaer UM, Sogaard A, Lu Q, Workman CT, Liang G, Jones PA, Gronbaek K: Equitoxic doses of 5-azacytidine and 5-aza-2'deoxycytidine induce diverse immediate and overlapping heritable changes in the transcriptome. PLoS One 2010, 5:e12994.

47. Topark-Ngarm A, Golonzhka O, Peterson VJ, Barrett B Jr, Martinez B, Crofoot K, Filtz TM, Leid M: CTIP2 associates with the NuRD complex on the promoter of p57KIP2, a newly identified CTIP2 target gene. J Biol Chem 2006, 281:32272-32283. Epub 32006 Sep 32271.

48. Larsson C, Skogseid B, Oberg K, Nakamura Y, Nordenskjold M: Multiple endocrine neoplasia type 1 gene maps to chromosome 11 and is lost in insulinoma. Nature 1988, 332:85-87.

49. Karnik SK, Hughes CM, Gu X, Rozenblatt-Rosen O, McLean GW, Xiong Y, Meyerson M, Kim SK: Menin regulates pancreatic islet growth by promoting histone methylation and expression of genes encoding p27Kip1 and p18INK4c. Proc Natl Acad Sci U S A 2005, 102:14659-14664. 
50. Lopez-Egido JR, Wang Y, Gronberg M, Grimfjard P, Wang S, Stalberg P, Skogseid B: Differentially regulated genes in MEN1-transfected BON cells using RT-differential display and oligonucleotide microarrays. Anticancer Res 2009, 29:1859-1866.

51. Stalberg P, Grimfjard P, Santesson M, Zhou Y, Lindberg D, Gobl A, Oberg K, Westin G, Rastad J, Wang S, Skogseid B: Transfection of the multiple endocrine neoplasia type 1 gene to a human endocrine pancreatic tumor cell line inhibits cell growth and affects expression of JunD, delta-like protein 1/preadipocyte factor-1, proliferating cell nuclear antigen, and QM/Jif-1. J Clin Endocrinol Metab 2004, 89:2326-2337.

52. Kidd M, Schally AV, Pfragner R, Malfertheiner MV, Modlin IM: Inhibition of proliferation of small intestinal and bronchopulmonary neuroendocrine cell lines by using peptide analogs targeting receptors. Cancer 2008, 112:1404-1414.

53. Jackson LN, Chen LA, Larson SD, Silva SR, Rychahou PG, Boor PJ, Li J, Defreitas G, Stafford WL, Townsend CM Jr, Evers BM: Development and characterization of a novel in vivo model of carcinoid syndrome. Clin Cancer Res 2009, 15:2747-2755. doi: 2710.1158/1078-0432.CCR-2708-2346. Epub 2009 Mar 2731

54. Kidd M, Nadler B, Mane S, Eick G, Malfertheiner M, Champaneria M, Pfragner R, Modlin I: GeneChip, geNorm, and gastrointestinal tumors: novel reference genes for real-time PCR. Physiol Genomics 2007, 30:363-370.

doi:10.1186/1756-8935-7-15

Cite this article as: Schimmack et al:: A mechanistic role for the chromatin modulator, NAP1L1, in pancreatic neuroendocrine neoplasm proliferation and metastases. Epigenetics \& Chromatin 2014 7:15.

\section{Submit your next manuscript to BioMed Central and take full advantage of:}

- Convenient online submission

- Thorough peer review

- No space constraints or color figure charges

- Immediate publication on acceptance

- Inclusion in PubMed, CAS, Scopus and Google Scholar

- Research which is freely available for redistribution 